ARTIGO

Recebido em: 08/03/2016

Aceito em: 10/11/2016

\title{
Biblioteca Rio-Grandense: um estudo de caso sob o viés da educação patrimonial
}

\author{
Rio-Grandense library: a case study under the focus of heritage \\ education
}

\author{
Marcia Carvalho RODRIGUES (marciarodriguesfurg@gmail.com)* - Pamela da Conceição \\ SANTOS (pdaconceicaosantos@gmail.com)** \\ * Professora da Universidade Federal do Rio Grande \\ ** Bibliotecária formada pela Universidade Federal do Rio Grande
}

\begin{abstract}
Resumo
Buscou-se investigar a importância da educação patrimonial no processo de reconhecimento da biblioteca enquanto instituição patrimonial e as possibilidades de atuação do profissional bibliotecário neste contexto. 0 estudo de caso teve como objeto de análise a Biblioteca Rio-Grandense, localizada em Rio Grande/RS. Os dados foram coletados através de questionário semiestruturado; as respostas obtidas foram categorizadas e analisadas segundo o método da Análise de Conteúdo. 0 estudo permitiu concluir que a instituição percebe a importância da participação do bibliotecário no processo de divulgação e reconhecimento patrimonial da biblioteca, bem como a importância cultural e patrimonial da Biblioteca Rio-Grandense para a comunidade.

Palavras-Chave: Biblioteca Rio-Grandense. Educação patrimonial Biblioteconomia.
\end{abstract}

\begin{abstract}
We sought to investigate the importance of heritage education in the process of recognition of library as heritage institution and performance opportunities for the professional librarian in this context. The case study was analyzed in the Rio-Grandense Library, located in Rio Grande/RS (Brazil). Data were collected through a semi-structured questionnaire; the answers were categorized and analyzed using the method of Content Analysis. The study concluded that the institution realizes the importance of the participation of librarians in the process of disclosure and financial statement recognition of library as well as the cultural and heritage importance of the Rio-Grandense Library to the community.

Keywords: Rio-Grandense Library. Heritage education. Library Science.
\end{abstract}



v. 22 , n. $48,2017$. p. $2-14$

ISSN 1518-2924

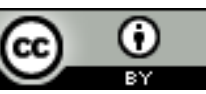




\section{INTRODUÇÃO}

A Biblioteca Rio-Grandense, ao longo de sua história, amealhou um vasto acervo, compreendido nos mais diversos tipos de documentos, tais como livros, mapas, obras raras, itens de iconografia, periódicos, dentre outros bens que representam seu patrimônio social. Esses itens registram importantes passagens do processo de constituição do povo gaúcho e brasileiro, revelando-se, portanto, ricas fontes de informação histórico-cultural nos âmbitos citadino, regional e nacional. Observa-se, no entanto, que apesar da instituição representar patrimônio cultural eminente, aos olhos da população local parece estar passando despercebida, tendo em vista os poucos sócios e a fraca procura por seus serviços fronte a uma cidade com mais de 200 mil habitantes ${ }^{1}$.

Neste ponto, sobrevieram as seguintes indagações: que iniciativas a Biblioteca RioGrandense tem empreendido no intuito de ser reconhecida como patrimônio cultural e histórico pela comunidade rio-grandina? Qual o papel do profissional bibliotecário neste contexto? De que forma a educação patrimonial pode contribuir neste processo?

À vista destas inquietações, esta pesquisa, oriunda do trabalho de conclusão de curso da autora, teve o intuito de investigar quais ações vem sendo empreendidas pela Biblioteca Rio-Grandense para se fazer percebida junto à população rio-grandina, tendo como fio condutor do estudo a educação patrimonial e as possibilidades de atuação do bibliotecário neste contexto. 0 artigo apresenta uma síntese do referido trabalho e inclui revisão de literatura, onde se discutiram as instâncias da memória no meio social, o patrimônio cultural e seus elementos constituintes, o papel das bibliotecas no processo de preservação e difusão dos bens culturais junto à sociedade, o significado de educação patrimonial e suas possibilidades de interação com a Biblioteconomia, e um breve histórico da Biblioteca Rio-Grandense e suas riquezas culturais. Na sequência são apresentados os procedimentos adotados para o desenvolvimento da pesquisa, enunciando sua classificação, universo e métodos para coleta e análise dos dados. Por fim, são apresentados os resultados a partir do conjunto de dados observados e as reflexões finais tecidas com base na revisão teórica e nas visitas técnicas realizadas à Biblioteca Rio-Grandense.

\section{MEMÓRIA, PATRIMÔNIO CULTURAL E BIBLIOTECAS}

A memória pode ser retratada, a princípio, como a capacidade humana de reter e agregar fatos do passado desencadeados por experiências ou situações vividas por um indivíduo que o marcaram de alguma forma, deixando resíduos em sua consciência. Entretanto, tal indivídio, como membro da sociedade, não constitui sua memória isoladamente. Halbwachs (1990) propõe a categorização da memória em duas instâncias: a primeira instância individual, onde é particularmente o homem quem evoca as lembranças; a segunda instância coletiva, quando os acontecimentos são compartilhados por uma comunidade.

Pollak (1992) atribui três elementos como constituintes da memória: a) os acontecimentos vivenciados pelo próprio indivíduo ou aqueles experimentados "por tabela", nos quais não esteve envolvido diretamente, mas que, como incidiram no grupo do qual ele faz parte, acabaram o atingindo de certo modo; b) os personagens, cujo contato pode se dar presencialmente ou "por tabela", onde a pessoa, de tanto saber ou receber informações sobre alguém, acaba pensando que a/o conhece, embora não tenha estado com ela/ele; c) e por fim, os lugares de memória, vinculados a lembranças.

Sobre os lugares de memória, Nora (1993, p. 13) considera que eles "nascem do sentimento de que não há memória espontânea". Conforme o passar do tempo, um grupo social acaba, inevitavelmente, tendo de remodelar suas estruturas e entrar em conformidade com parâmetros sociais vigentes. Mas, para evitar que isso altere drasticamente as particularidades de seu meio, os indivíduos criam mecanismos para conservá-las. Nesse ponto, as bibliotecas, arquivos e museus surgem como espaços de memória, uma vez que primam por manter preservadas a produção intelectual, histórica e cultural de uma coletividade sob a forma de registros.

\footnotetext{
1 Segundo o Instituto Brasileiro de Geografia e Estatística (IBGE), a população rio-grandina estava estimada, em 2015, em 207.860 habitantes. (IBGE, 2016)
} 
Seguindo neste contexto, tem-se o patrimônio cultural, o qual engloba uma diversidade de bens culturais, bens estes que contribuem para a preservação da memória. Segundo Ghirardello, Spisso e Faria (2008), o patrimônio cultural pode ser entendido como a soma de bens culturais, de ordem material ou imaterial, que faz referência à identidade e à memória da sociedade em seus diversos segmentos.

Resgatando Mentz (2011), podemos compreender o que seriam as ordens material e imaterial do patrimônio cultural. No contexto material, o patrimônio cultural representa os meios de produção de adaptação humana ao ambiente e sua organização social, fazendo parte deste conjunto: monumentos, edifícios, sítios arqueológicos, obras de arte, esculturas, documentos, instrumentos, móveis, cartografias, fotografias, gravuras, entre outros. A sua condição materializada permite denominá-los, igualmente, de bens tangíveis, pois são itens que podem ser tocados. Já o patrimônio cultural no plano imaterial, segundo o autor, está vinculado ao conhecimento, à técnica, ao saber, ao saber-fazer e às manifestações de um povo, englobando seus valores, hábitos, costumes, ideologias, crenças, festejos e manifestações artísticas, sendo caracterizados como bens intangíveis devido ao fato de não poderem ser tocados. Seu compartilhamento ocorre na oralidade, convivência e ensino.

Neste contexto estão inseridas as bibliotecas. De caráter fundamentalmente patrimonial, as chamadas bibliotecas históricas, entidades que lidam com livros e arquivos antigos, estes compreendidos como unidades de registro dos conhecimentos antepassados que servem de aporte ao saber gerado no tempo presente, representam assim elementos do patrimônio cultural de uma sociedade. (PEDRAZA GARCIA, 2014).

É, portanto, de responsabilidade das bibliotecas históricas zelar pela preservação documental e difusão democrática destes conhecimentos nos grupos sociais em que estão situadas, pois como esses registros dizem respeito ao patrimônio cultural desses grupos, seus membros têm o direito de conhecê-los, usufruir deles e preservá-los. Esse processo de mediação previne a perda do conhecimento e consequentemente do patrimônio cultural, porque no uso passam a ser reaproveitados, recuperados e conservados "vivos". (PEDRAZA GARCIA, 2014).

A biblioteca histórica como mantenedora dos bens patrimoniais deve empregar ações para divulgá-los e dar-lhes visibilidade, envolvendo a comunidade no intuito de que esta os investigue e aprenda a reconhecer a sua importância, passando a respeitá-los e a valorizá-los. Uma forma de desenvolver este processo é através da ativação dos mecanismos da Educação Patrimonial.

Cabe aqui antecipar a apresentação da instituição que serviu como objeto deste estudo, a Biblioteca Rio-Grandense, uma vez que poderá ser observado, mais adiante neste texto, que tal instituição se caracteriza como entidade privada, sem fins lucrativos. Não é, portanto, biblioteca pública, mas possui sim, características de uma biblioteca histórica, uma vez que significativa parcela de seu acervo é constituída de obras de grande valor histórico e cultural, servindo de referência a importantes pesquisas históricas sobre o município e arredores, o Estado e mesmo sobre o país, especialmente devido à sua riquíssima coleção de jornais antigos e obras raras.

\subsection{Educação patrimonial}

Os esforços em favor do patrimônio cultural no Brasil adquiriram relevância durante a Era Vargas, com a fundação do Instituto do Patrimônio Histórico e Artístico Nacional (IPHAN), em 1937. Ao órgão de status federal competem as missões de resguardar e difundir os bens culturais nacionais para usufruto tanto das gerações presenciais quanto posteriores e orientar legalmente como devem ser tratados pela sociedade. 0 tema da educação patrimonial, no entanto, só foi introduzido no país a partir dos anos 1980.

Horta (1999, p. 6) acredita que educação patrimonial "trata-se de um processo permanente e sistemático de trabalho educacional centrado no Patrimônio Cultural como fonte primária de conhecimento e enriquecimento individual e coletivo.". Acerca disso, observa-se que a educação patrimonial condiciona o patrimônio à posição de objeto de estudo, já que sendo ele resultado do trabalho humano e acumulado através dos tempos, carrega em si dados de outrora, os quais, se explorados, desencadeiam a produção de novos conhecimentos.

Para Machado (2004, p. 114 apud CUNHA; CROASARA, 2011, p. 61) educação patrimonial significa "implementação de ações educativas de investigação, aproximação e valorização do patrimônio cultural.”. 
Neste ponto, a educação patrimonial pretende voltar a atenção do educando ao patrimônio pela experimentação e despertar nele o senso crítico para que possa compreendê-lo e lhe imputar valor, cujo empreedimento pode ocorrer de diversas formas. Portanto, podemos interpretá-la como um conjunto de práticas pedagógicas pautadas nos bens culturais, condicionados estes como recursos de informação, destinados a instruir as pessoas, conforme experimentação e análise reflexiva. A partir da significação destes recursos, as pessoas passam a reconhecer sua função social e daí a estabelecer um relacionamento favorável à valorização e à preservação do patrimônio cultural.

0 processamento da educação patrimonial atende a uma metodologia que, segundo o raciocínio proposto por Grunberg (2007), compreende as seguintes fases:

a) observação: fase onde o indivíduo, ao ter contato com o bem cultural, faz o reconhecimento de sua função e significado;

b) registro: nesta fase se buscam fixar os conhecimentos obtidos por meio da escrita ou descrição, possibilitando aos indivíduos uma observação mais aprofundada destes dados;

c) exploração: momento em que o bem cultural se torna um objeto de discussão, cujo investigador, utilizando também outras referências (centros informacionais, documentos, pessoas próximas, por exemplo), começa a analisá-lo criticamente;

d) apropriação: nessa etapa o indivíduo, já consciente do que o bem cultural representa, passa a interagir no processo de apoderamento, valorização e cuidado deste.

Destarte, a educação patrimonial viabiliza a transposição do indivíduo da condição de espectador, cuja apreciação muitas vezes se dá pela mera reprodução de valores calcados socialmente, tornando-a vazia ou irreal, já que o receptor não percebe as razões de existirem, a uma apreciação proativa, onde ao interagir com o objeto, podem averiguá-los em toda a sua complexidade histórica e funcional, aprendendo a discernir a importância destes bens, em o seu nicho cultural social, enquanto suportes mantenedores e difusores de cultura.

Grunberg (2000) afirma que a identificação cultural ocorre por intermédio dos produtos materiais e as maneiras pelas quais estes são empregados socialmente nos credos, costumes, tradições, expressões artísticas, ciência e tecnologia, correspondendo aos bens culturais. À vista disso, os artefatos e manifestações figuram como bens à medida que oportunizam aos demais conhecer uma comunidade no que tange aos seus hábitos, ideologias e evolução histórico-social. Tais manifestações, portanto, deteriam feições culturais em razão do gradativo processo produtivo onde conhecimentos, regras e trejeitos foram se constituindo, sendo incorporados e retransmitidos por indivíduos num determinado ambiente, compondo assim uma unidade organizacional com características e legado próprios, fundamentando o patrimônio.

Os bens culturais também possuem ordem consagrada na qual são reconhecidos e salvaguardados judicialmente como monumentos, prédios, praças, fotografias; e não consagrada como ritos, festejos populares, danças, saberes comuns, vivenciados cotidianamente. (GRUNBERG, 2007)

Independentemente da categoria na qual estejam enquadrados, deve haver a apreciação dos bens culturais em toda a sua extensão, pois como consequência do trabalho humano individual ou conjunto, representam importantes partículas de sua identidade e memória, as quais sem estes registros não podem ser preservadas. Ao mesmo tempo, é imprescindível sua utilização para que se "[...] tornem vivos e cumpram a função de transmitir a memória de sua época.". (GRUNBERG, 2000, p. 162)

Segundo Bastos (2006), portanto, a educação patrimonial tem a possibilidade de proceder formal ou informalmente. Quando em plano formalizado, está vinculada às escolas e institutos de caráter similar. Já o segundo plano, informal, a direciona para as comunidades, devendo as ações educativas estar sempre alinhavadas ao contexto das comunidades onde estão sendo desenvolvidas. Algo necessário, obviamente, porque se o que é pretendido é o resgate cultural destes grupos, adotando como fonte de apreciação seu patrimônio, nada mais sensato do que voltar todas as atenções ao seu contexto, revocando igualmente elementos originários e pertinentes. 


\subsubsection{Biblioteconomia e educação patrimonial: possibilidades de interação}

Carteri (2004) considera que a Biblioteconomia, enquanto uma das especificidades da Ciência da Informação, se beneficia do aporte metodológico das demais ciências, especialmente das humanidades, para analisar a informação, se debruçando nas questões ligadas ao suporte, organização e disponibilização.

Com base nestas acepções, discorre-se acerca do escopo da Biblioteconomia, acreditando-se que este ramo seja permeado pelo caráter interdisciplinar, já que não se estabelece ou atua à parte, mas sim em complementaridade a outras áreas humanísticas do conhecimento, buscando nos aspectos antropológicos, históricos, éticos, filosóficos, políticos, econômicos, ambientais, informacionais, culturais, artísticos, literários, dentre outros, os insumos necessários para compreender a sociedade e suas peculiaridades no intuito de interagir com a mesma.

Num segundo momento, interpreta-se que o campo biblioteconômico possui como foco investigativo a informação, seus modos de representação e veiculação, assumindo uma postura mais técnica. A informação está presente em diversos nichos científicos e cada um apresenta panoramas e necessidades específicos - é preciso que a Biblioteconomia interaja com estes campos, visando à plena percepção sobre as formas sobre como ela é gerada, possibilitando estabelecer os critérios e procedimentos técnicos adequados para seu registro, armazenamento, ordenação, disseminação, recuperação, acesso e uso pelos consulentes.

Acerca dos profissionais bibliotecários, estes têm inúmeras possibilidades de atuação, partindo da biblioteca propriamente dita (seja ela escolar, universitária, especializada, pública, comunitária, especial ou histórica), até outros espaços como centros de documentação, editoras, repositórios institucionais e empresas, por exemplo. Dias (2000, p. 71) colabora ao referir algumas das funções implicadas nas rotinas biblioteconômicas, sendo estas: "[...] desenvolvimento de coleções (seleção dos materiais), classificação, catalogação, referência, pesquisa em sistemas de recuperação da informação, administração (planejamento estratégico, estudo do usuário, educação do usuário), etc."

Cumpre a estes profissionais, com base na sua formação acadêmica e reconhecimento legal da profissão, zelar pelos aspectos técnicos, administrativos, culturais, sociais, educacionais e preservacionais da biblioteca, contribuindo com sua desenvoltura na prestação de serviços de qualidade perante a comunidade usuária.

O bibliotecário pode ser percebido, portanto, como um elo entre o saber ou entre a informação e as pessoas, devendo promover esforços para estimular o gosto e o hábito de ler, divulgar e difundir a informação irrestritamente no meio social, viabilizando seu resgate e consumo pelos indivíduos que dela necessitam, subsidiando a formação educacional do ser humano. Em razão disso, Carteri (2004, p. 41) acredita que os “[...] bibliotecários são também educadores patrimoniais, visto que também atuam com a memória.".

Retomando Carteri (2004), observa-se que esta analisa a interação da Educação Patrimonial com a Biblioteconomia, desenvolvendo um sistema denominado Metodologia da Educação Patrimonial Biblioteconômica, o qual abrange um conjunto de abordagens que buscam evidenciar meios pelos quais é possível desencadeá-la. São estes:

a) abordagem arquitetônica: submete o prédio da biblioteca à investigação, propondo questões de análise como: o posicionamento do edifício, trajetória de implantação, personagens envolvidos etc., cujas respostas seriam obtidas através de pesquisas biográficas ou presenciais com os sujeitos participantes, consultas a fontes geográficas, arquitetônicas, entre outros;

b) abordagem documental: submete o acervo da biblioteca à investigação, propondo questões de análise como: as temáticas do acervo, organização, os documentos e seus formatos, consulentes dos materiais, entre outros. 0 processo investigativo pode abranger pesquisas com gestores e mantenedores do acervo, as tipologias documentais apresentadas, a gênese do arranjo de acervos, entre outros;

c) abordagem bibliográfica: submete o livro e demais itens à investigação, sugerindo como aspectos de análise: o contexto histórico dos documentos, métodos para sua criação, tipologias e empregabilidade social, entre outros, possibilitando diferentes módulos de atividades, tais como história do livro, tipos de bibliografias, consulta às editoras, pesquisa com autores/editores, entre outros;

d) abordagem multidisciplinar: incorpora as abordagens já indicados, representando a opção mais completa para ser trabalhada nos institutos educacionais, pois reúne alunos, 
professores e o mediador bibliotecário e, conforme o tema escolhido, torna-se possível elaborar atividades nas distintas disciplinas escolares levantando questões vinculadas ao tema comum.

Tendo estas propostas como amparo, as bibliotecas podem adaptá-las à sua realidade e projetar variadas atividades culturais como oficinas de leitura, hora do conto, pesquisas em documentos históricos como livros ou fotografias para conhecer a história da cidade, estabelecer, em parceria com as escolas, uma programação de visitas guiadas à biblioteca para que os alunos possam conhecê-la e explorá-la, dentre outras possibilidades.

\subsection{Biblioteca Rio-Grandense}

A origem da Biblioteca Rio-Grandense remonta ao ano de 1846, quando o comerciante português João Barbosa Coelho e mais 21 membros da sociedade rio-grandina tiveram a iniciativa de fundar no extremo sul do país uma entidade privada, denominada inicialmente Gabinete de Leitura, inspirada no gabinete da Corte Real Portuguesa.

A instituição passou por mudanças de endereço ao longo dos anos, grande parte destas em decorrência de condições estruturais inadequadas para uma biblioteca e seu acervo, além de um fator agravante, presente desde os primórdios de sua fundação: a escassez de recursos financeiros. Silva (2011, p. 61) atenta para dois importantes fatos vinculados à história da instituição: "[...] a mais famosa intempérie foi o caso do tesoureiro Severo e o maior louro a criação dos cursos noturnos e gratuitos de alfabetização.". Para fim de compreensão geral, sucedeu que o comerciante português Manoel Alves Pinto, apelidado popularmente de Manuel Severo por seu temperamento intolerante, fez-se sócio do Gabinete de Leitura em 1870, passando à tesouraria em 1873. Frequentemente concedia quantias para cobrir despesas ou dívidas da instituição. Todavia, perante um desentendimento com a diretoria resolveu deixar o cargo e reclamar judicialmente 131.900 contos de réis devidos pela instituição, ocasionando a penhora do acervo. Felizmente, Francisco Antonio Affonso, o Barão de Vila Isabel, tomando conhecimento do fato, quitou pessoalmente a dívida, impedindo a perda dos bens patrimoniais amealhados arduamente. (BIBLIOTHECA..., 1996)

A partir dessa intervenção, sucederam drásticas modificações relativas ao Gabinete de Leitura, cujo Barão de Vila Isabel, já empossado da presidência, o transferiu de endereço e compôs novos estatutos. No dia 4 de julho de 1878 o Gabinete galgou o status de Biblioteca Rio-Grandense, "[...] sociedade de recreio espiritual e de difusão cultural.". (BIBLIOTHECA..., 1996, p. 10)

Tendo o caráter sócio-educativo revitalizado, a biblioteca começou a oferecer aulas gratuitas à população, visando às séries primárias e secundárias, além dos cursos de cunho técnico ou especializado. Sanfelice (1998) destaca a significativa contribuição da Biblioteca Rio-Grandense para a criação da Universidade do Rio Grande (atual Universidade Federal do Rio Grande - FURG), pois foi nas instalações da biblioteca que se ministrou o primeiro curso universitário de Engenharia Industrial, cuja parceria durou de 1954 até 1961, tendo ainda a Rio-Grandense participado na criação das faculdades de Direito, Economia, Filosofia e Medicina.

A problemática da sede própria só encontrou resolução em 1902, quando a Biblioteca recebeu da Câmara Municipal seu antigo prédio reformado.

Atualmente, a instituição encontra-se situada na Rua General Osório, n.o 454, e atende à população local de segunda a sexta-feira, com expediente das $9 \mathrm{~h}$ às $17 \mathrm{~h}$, servindo de fonte informacional à pesquisa escolar, acadêmica e particular da comunidade usuária. Dispõe dos seguintes setores: Atendimento e referência, Processamento técnico, Sala de pesquisa comum, Sala de pesquisa especializada, Acervo geral (distribuído em cinco pavimentos), seis salas de acervos históricos, além da sala da Direção e um espaço alugado à prefeitura, onde está instalada a Biblioteca Pública Monteiro Lobato, designada ao público infantil. Em termos de interação virtual, a Biblioteca Rio-Grandense possui perfil na rede social Facebook e dispõe de página própria, no seguinte endereço: http://www.bibliotecariograndense.com.br. Neste, é possível acessar o catálogo on-line e requisitar o atendimento à distância, o qual possibilita o envio de fotocópias de jornais e obras raras.

Os serviços prestados pela entidade são atendimento, referência, consulta local, digitalização de documentos e reprografia, ao público em geral, e empréstimo domiciliar de obras de ficção e poesia aos sócios. Por se tratar de uma entidade privada, seu orçamento se 
mantém, principalmente, através do pagamento de taxas específicas de serviços prestados tanto na sala comum como na especializada.

0 acervo possui caráter fechado, ou seja, o acesso se restringe aos funcionários. Com aproximadamente 465.000 volumes, é um dos maiores acervos históricos do Rio Grande do Sul e um dos principais a nível federativo. Sua composição inclui livros, jornais, folhetos, obras de referência (dicionários, enciclopédias), obras de cunho didático e técnico, quadros, mapas, cartas náuticas, plantas, CDs, DVDs, fotografias e microfilmagens, os quais estão distribuídos em cinco pavimentos, além das salas especiais. Atualmente a instituição realiza a compra somente de obras de ficção.

Conforme o Estatuto da Biblioteca Rio-Grandense, percebe-se que "[...] o patrimônio social é constituído de imóveis, títulos e outros bens e ainda pelos livros, coleções, arquivos.". (BIBLIOTHECA RIO-GRANDENSE, 1941, Art. 3으. Estes itens registram passagens, acontecimentos e aspectos significativos do processo de formação e assentamento do povo gaúcho e brasileiro, simbolizando importantes fontes de informação histórico-culturais, como por exemplo o Lenço Farroupilha utilizado na Guerra dos Farrapos, o qual, segundo informação obtida junto à própria instituição, apresenta manchas que seriam de sangue do guerrilheiro que o utilizava, escurecidas pela ação do tempo. Alocadas em espaços privativos, as coleções especiais foram em grande parte doadas, tendo inclusive algumas pertencido a personalidades de destaque nos séculos XIX e XX, cedidos por estes ainda em vida ou postumamente. Dentre essas coleções pode-se citar a Sala Brigadeiro José da Silva Paes, composta por um acervo com aproximadamente 3.900 obras de autores gaúchos, abordando a formação do Rio Grande do Sul, consistindo em um dos mais amplos acervos no tocante ao tema; a Sala Fernando Duprat, a qual dispõe de mapoteca, que contém 1.025 itens, englobando mapas, cartas náuticas e plantas acerca da geografia local, regional, nacional e internacional, além de concentrar grande parte da coleção de obras raras; e a Sala Almirante Tamandaré, composta de acervo poliglota com cerca de 70 itens, no qual predominam as obras cujo tema está relacionado à arte naval, provindos quase totalmente de doação - a manutenção do espaço físico desta sala é mantida pela Marinha do Brasil, a qual encaminha pessoal para realização de reparos como pintura e restauro de móveis.

\section{METODOLOGIA}

A pesquisa se caracteriza como um estudo de caso, pois delimitou-se a averiguar que medidas a Biblioteca Rio-Grandense tem executado no sentido de se tornar reconhecida enquanto patrimônio histórico-cultural da cidade do Rio Grande sob o viés da educação patrimonial. Segundo Yin (2001), o estudo de caso pode ser entendido como a análise de um objeto em suas reais condições, pressupondo-se que tal contexto teria ligações, vindo a intervir no objeto investigado.

0 universo da pesquisa abarcou a equipe de trabalho da instituição, incuindo bibliotecários e membros do corpo diretivo, o que totalizou 9 (nove) respondentes. Excluiramse, aqui, os estagiários, uma vez que não possuem vínculo empregatício com a instituição.

Para o levantamento de dados foi elaborado um questionário contendo questões abertas e fechadas, cuja aplicação procedeu por meio de visitas à Biblioteca Rio-Grandense e entrega das cópias aos sujeitos selecionados, junto a um termo de esclarecimento que atesta seu consentimento em participar da pesquisa e o uso das respostas fornecidas.

A técnica utilizada para a análise das respostas foi a Análise de Conteúdo, método proposto por Lawrence Bardin (1977), cumprindo as etapas de: pré-análise, cujas ideias iniciais são retomadas e organizadas sistematicamente, contribuindo para a formulação de um plano investigativo mais preciso para exploração das informações regisyg $\backslash y \backslash$ tradas; a exploração do material, onde ocorrem a codificação, decomposição ou enumeração documental dos textos em estado bruto e recorte em unidades de registro (palavra, tema, objeto, personagem, por exemplo) significativas à categorização do conteúdo e contagem frequencial, agrupados tematicamente gerando as categorias de assunto; e o tratamento dos dados obtidos e interpretação, que consiste em captar os conteúdos manifestos e latentes contidos em todo o material coletado. 


\section{RESULTADOS E DISCUSSÃO}

A fim de preservar a identidade dos respondentes, aos mesmos se atribuíram as seguintes denominações: Respondente $A$, Respondente $B$, Respondente $C$, Respondente $D$, Respondente E, Respondente F, Respondente G, Respondente H e Respondente I. Conforme o levantamento dos dados, procedeu-se à apresentação, análise e discussão dos mesmos. Para cada questão respondida foram geradas categorias de assunto conforme a Análise de conteúdo as quais são demostradas a seguir.

4.1 Questão 1 - Você acredita que a Biblioteca Rio-Grandense seja reconhecida pela comunidade como elemento integrante do patrimônio histórico-cultural local? (Não). (Sim). Justifique sua resposta.

A partir das respostas obtidas nesta questão, emergiram as seguintes categorias: Temporalidade, Valor cultural sublimado e Pouco uso popular.

Observa-se que na percepção dos pesquisados o reconhecimento da biblioteca como patrimônio está atrelado, na atualidade, ao critério de temporalidade devido ao fato desta instituição ser a mais antiga a operar no Estado do Rio Grande do Sul, tendo sido outrora um centro cultural de destaque no cenário local. 0 decréscimo de sua relevância cultural se atesta em função do baixo interesse e procura dos munícipes por seus serviços.

Cabe ponderar que, embora uma instituição esteja há muito tempo em atividade num determinado local, isso não implica, necessariamente, atribuir-lhe qualificação patrimonial, pois mesmo presente fisicamente, o grupo social do entorno ainda assim pode desconhecer sua trajetória histórica e sob que aspectos representaria um bem cultural local devido à falta de interação com o bem em questão, estando assim desprovido de fundamentos verdadeiros (teóricos, afetivos, culturais, entre outros) que o levariam a refletir criticamente sobre a instituição.

4.2 Questão 2 - Há o planejamento de estratégias (ações, projetos etc.) com o intuito de dar visibilidade à biblioteca e ao seu acervo junto à comunidade rio-grandina? (Não). (Sim). Quais?

Como resultado da análise das respostas a esta questão, emergiram as seguintes categorias: Centralização do planejamento organizacional e Realização de atividades.

Acerca do planejamento estratégico e projetos para dar visibilidade popular à biblioteca e seu acervo, percebe-se que, a princípio, medidas são estabelecidas para promover a biblioteca socialmente, visto que há a realização de atividades envolvendo a comunidade e a comunicação com a mídia local. Todavia, o discurso apresentado pela equipe denota poucas possibilidades de participação e interação nos trâmites gerenciais devido à responsabilidade e poder de comando permanecerem centralizados hierarquicamente.

Tal contexto permite avaliar que a figura do bibliotecário não apresenta significativa relevância para as tomadas de decisão na instituição, cabendo-lhe, primordialmente, desempenhar atividades de tratamento técnico e atendimento aos usuários. Observe-se aqui que tal fato se deve à presença de uma estrutura administrativa engessada, estabelecida nos primórdios da criação da Biblioteca, e que deveria ter passado por revisão ou atualização ao longo do tempo, uma vez que na época de criação da Biblioteca Rio-Grandese, em 1847, não havia cursos de formação de profissionais bibliotecários no Brasil.

Hoje esta situação se mostra desfavorável, tanto à instituição quanto ao profissional, uma vez que restringe o trabalho do(s) bibliotecário(s), comprometendo negativamente sua percepção organizacional por dificultar-lhe a verificação aprofundada de problemas, questões sobre as quais poderia refletir e buscar meios para solucioná-los, uma vez que não há previsão de vaga para bibliotecário como membro do corpo diretivo da biblioteca devido à estrutura hierárquica vigente. Não se justifica deixar este profissional à parte dos processos gerenciais, pois com sua formação acadêmica e experiência laboral, tem condições de auxiliar a administração de uma biblioteca na elaboração conjunta de ações pautadas no marketing cultural e educação patrimonial, o que certamente resultaria em um maior interesse popular pelos serviços da instituição estudada. 
4.3 Questão 3 - A biblioteca realiza ou já realizou ações culturais? (Não). (Sim). Quais?

A partir das respostas obtidas na questão 3, emergiram as seguintes categorias de análise: Serviços culturais restritos e Entrave financeiro.

As respostas indicam que, em geral, as ações culturais empreendidas pela instituição tendem a seguir uma estratégia linear e pouco variada. Verifica-se, igualmente, que a gestão vem tentando sanar gradativamente esta questão, contudo, maiores esforços têm sido impedidos devido às condições financeiras da biblioteca, indicando a necessidade de auxílio externo para solucionar seus problemas.

Uma das ações citadas pelos respondentes foram os encontros da Academia RioGrandina de Letras (ARL), porém deve-se salientar que os mesmos são de autoria da ARL, que para realizá-los simplesmente aluga o espaço institucional, prosseguindo suas ações independentemente. Pensando no quesito do apelo popular, cogita-se a necessidade de maior ênfase à projeção de bens e serviços culturais no sentido de expandi-los, conferindo mais atratividade à organização perante a comunidade envolvida.

A Biblioteca Rio-Grandense possui acervo documental rico, comporta em si elementos importantes sobre a constituição histórico-cultural citadina, regional e inclusive nacional, o que significa infindas possibilidades de estudo, pesquisa, investigação. Porém, passa despercebida pelo senso comum devido à escassa divulgação. Portanto, utilizar os recursos históricos (primando, obviamente, por sua preservação física) no delineamento das dinâmicas culturais contribuiria para a sua diversificação, igualmente oportunizando à comunidade em geral explorar e reconhecer as potencialidades da instituição.

Foi posto que a atual situação financeira têm inibido a expansão de ações culturais pela referida biblioteca, cujas dificuldades nesse contexto, segundo informações obtidas junto ao Diretor de acervo ${ }^{2}$, estariam relacionados à baixa arrecadação de verba advinda dos poucos sócios afiliados à instituição e ao escasso auxílio popular, fatos que frequentemente têm condicionando a atual gestão a empregar primordialmente o capital coletado no pagamento de contas essenciais, possibilitando ao menos o funcionamento e manutenção dos serviços pela Biblioteca Rio-Gradense, que inclusive chegou a ter problemas na quitação de impostos fiscais, contraindo dívidas com a Federação e beirar a penúria pela crítica falta de insumos.

Tendo em vista a complicada situação em que se encontra a instituição, propor-se-ia à gestão, como medida alternativa, evocar o auxílio do departamento de cultura da prefeitura local, bem como solicitar a parceria de professores e acadêmicos do curso de Biblioteconomia da FURG para o desenvolvimento de projetos voltados ao marketing institucional e atividades culturais. Da mesma maneira, a longo prazo e após a solução dos problemas financeiros emergenciais, poderiam ser pensados projetos para acionar as agências de fomento federais e privadas destinadas a esse setor.

\subsection{Questão 4 - Em caso de resposta negativa para a questão 3, aponte quais teriam sido} os principais motivos pelos quais a biblioteca não investe em ações culturais.

Em relação à questão de número 3 , não houve respostas negativas, portanto não há respostas para a questão 4 .

4.5 - Questão 5 - Caso você fosse desenvolver ações visando à divulgação e à popularização da Biblioteca Rio-Grandense, que atividades você promoveria?

A partir das respostas decorrentes da questão número 5 , emergiram as seguintes categorias: Práticas literárias, Uso do acervo e Público direcionado.

Em relação a quais atividades desenvolveriam para divulgar a Biblioteca RioGrandense, embora haja similaridade nos discursos, num aspecto geral os participantes demonstram iniciativa em articular meios no intuito de alavancar culturalmente a biblioteca, colaborando ainda mais ao propor estratégias diferentes daquelas já efetuadas pela instituição. A sugestão de introduzir as obras raras no contexto das ações culturais permite avaliar que na percepção dos funcionários inquiridos, estes elementos possuem valor atrativo, certamente por causa de sua historicidade e teor informacional, fatores que presumivelmente despertariam a curiosidade das pessoas, devendo assim ser compartilhados com as mesmas.

Sem eximir os demais nichos populacionais, porém focando na parcela jovem, a

20 cargo de Diretor de acervo da Biblioteca Rio-Grandense é, atualmente, desempenhado pelo prof. Dr. Mauro Póvoas (Instituto de Letras e Artes - ILA/Universidade Federal do Rio Grande - FURG), o qual fez parte da banca avaliadora deste trabalho. 
realização de saraus seria um eficaz modo de atraí-los, porque geralmente os livros de ficção e poesia são amplamente consumidos entre adolescentes e a Biblioteca Rio-Grandense investe bastante neste tipo de literatura. Logo, haveria a oportunidade de conclamar estes usuários potencias caso fossem desenvolvidos saraus, clube literário, rodas de leitura e discussão de temáticas abordadas nas aulas dos ensinos fundamental e médio, oficinas que trabalhassem os traços gaúchos como escritos de dança, música, artes plásticas, enfim, os benefícios decorrentes destas ações seriam mútuos: o público jovem inferiria novos significados e utilidade à Biblioteca Rio-Grandense e a entidade se tornaria um dispositivo capaz de complementar, despertar a apreciação pela leitura, bem como reforçar as perspectivas da cultura e regionalidade, tendo como aporte as investigações históricas no acervo.

\subsection{Questão 6 - 0 que você entende por educação patrimonial?}

As respostas obtidas resultaram nas seguintes categorias de análise: Valorização, Preservação e Conscientização popular.

Parte das concepções expostas relacionaram o significado de educação patrimonial basicamente à valorização de bens legados, sem explicitar porque ou quais fundamentos conduziriam o indivíduo a valorizar esses itens interpretados como frutos de uma herança. Paralelamente, outros respondentes concluem que esta visa à conscientização dos indivíduos sobre a importância do patrimônio histórico-cultural que eles possuem. A partir disso, foi possível constatar que existe conhecimento parcial referente ao tema indagado.

Em verdade, educação patrimonial não se confina ao ato de valorar, muito menos remete a algo que pode ser estabelecido prontamente e dado a alguém, pois constitui um processo de ensino contínuo, o qual toma como fontes de análise os bens culturais na intenção de aproximar as pessoas desses elementos justamente para que, no contato frequente, possam conhecê-los, examiná-los, refletir sobre sua função e relevância. Em estado de plena consciência, os indivíduos terão bases para respeitar os bens, apropriando-se dos mesmos.

Assim, verifica-se a necessidade dos indivíduos questionados terem diálogos aprofundados em conjunto no intuito de confluírem, construírem valores consensuais acerca do tema para que possam trabalhar essa questão harmonicamente. Para tal, seria benéfico convocar palestras, seminários, oficinas e cursos, promover pesquisas teóricas, sessões e rodas para exposição, questionamento e debates sob o foco da educação patrimonial, sem descuidar de demais temas vinculados a ele como as atividades culturais, mediação e papel do educador/mediador, por exemplo. Isto, agregado às suas competências profissionais, proporcionaria maior embasamento para delinear os objetivos de seu trabalho, o perfil da comunidade e os segmentos culturais aos quais possam se destinar, e as ações que pretendam executar de forma a contemplar e atender às demandas assinaladas pelo público alvo.

\subsection{Questão 7 - Você percebe o profissional bibliotecário como elemento importante no processo de promoção e reconhecimento de bibliotecas enquanto instituições patrimoniais? (Não). (Sim). Justifique sua resposta.}

A partir das respostas obtidas na questão 7 , emergiram as seguintes categorias: Divulgação e Preservação.

Sobre a significância do bibliotecário no processo de promoção patrimonial da biblioteca, percebe-se que os participantes acreditam na importância deste se envolver no processo de reconhecimento patrimonial das bibliotecas, estando seu papel vinculado primordialmente à preservação dos registros e artefatos do acervo, portador do patrimônio institucional, à divulgação cultural, deixaram em suspenso sob quais enfoques e como o bibliotecário poderia atuar nessa questão, e ao conjunto de atividades procedidas na entidade biblioteca.

Com base nas respostas obtidas, observa-se que no caso da Biblioteca Rio-Grandense, as atividades dos bibliotecários estão vinculadas essencialmente às rotinas de tratamento técnico da informação e atendimento ao público, posto que as decisões gerenciais ficam por conta da diretoria. Entretanto, reitera-se que se os gestores pretendem retomar as iniciativas culturais antes promovidas na instituição, poderiam observar mais a fundo o papel destes profissionais e incluir sua participação no planejamento destes prospectos, não lhes aferindo somente o exercício das questões operacionais, pois analisando a formação da classe biblioteconômica é possível averiguar que há o devido preparo para lidar com o planejamento de bens e serviços próprios às bibliotecas, investigar o perfil e as necessidades da comunidade servida, disseminar a informação adequadamente de modo a incentivar a cultura e educação 
dos usuários. Enfim, some-se a isto o know-how agregado pelos anos de interação com o público e se tem profissionais preparados para lidar com o planejamento de serviços e bens inerentes às bibliotecas, conhecendo o perfil e as necessidades da comunidade servida, disseminando a informação de modo a incentivar a cultura e educação de seus usuários. Conclui-se, a priori, que os bibliotecários teriam condições razoáveis de contribuir na causa.

Contudo, as respostas permitem ainda asseverar que a educação patrimonial implica dois vieses. 0 primeiro relacionado à instituição que pode explorar e apoiar potencialidade do bibliotecário neste aspecto. E o segundo relativo ao próprio profissional, quando inserido no setor cultural organizacional, que deve ter uma postura proativa e buscar aprimorar sua atuação no sentido de obter conhecimento acerca da mediação cultural, seu papel enquanto mediador, da promoção de ações culturais, os benefícios disso para a comunidade receptora e no que isso influencia a relação desta com a instituição promotora das ações, investigar outras realidades desvendando que trabalhos de foro cultural instituições similares desempenham para resgatá-las e/ou adaptá-las ao contexto onde operam, desenvolver um diálogo sensível com a população do entorno procurando saber quais atividades gostariam de ter à disposição, de modo a ampliar suas competências e desenvolver um trabalho proveitoso.

\section{CONSIDERAÇõES FINAIS}

A elaboração e a execução desta pesquisa possibilitaram o cumprimento dos objetivos determinados no intuito de investigar a Biblioteca Rio-Grandense e as estratégias adotadas pela instituição no sentido de ser reconhecida como patrimônio histórico-cultural no município do Rio Grande, verificando a importância do bibliotecário em participar deste processo e suas possibilidades de atuação através da educação patrimonial.

Analisando as falas dos respondentes, estes conceberam que o reconhecimento da biblioteca como patrimônio está atrelado na atualidade ao critério de temporalidade devido a ser a mais antiga instituição deste caráter a operar no Estado do Rio Grande do Sul, sendo em outrora um centro cultural de destaque no cenário local.

No que tange ao planejamento estratégico para dar visibilidade à biblioteca e seus bens perante a comunidade, a princípio se observa que medidas são estabelecidas para promover a biblioteca socialmente, visto que há realização de atividades envolvendo a comunidade e a comunicação com a mídia local. Porém, evidenciam-se limitadas possibilidades de interação nesses processos, pois a responsabilidade do poder decisório está centrada hierarquicamente no âmbito da presidência.

A biblioteca tende a seguir uma estratégia linear e pouco diversificada no desenvolvimento de ações culturais, considerando que durante os relatos não houve a menção de outras práticas além das recorrentes e que maior esforço tem sido impedido devido às condições financeiras da biblioteca, indicando a necessidade de auxílio externo para solucionar seus problemas. Logo, verificou-se a necessidade de haver mais empenho no planejamento de bens e serviços no intuito de expandi-los e tornar a instituição mais atrativa à comunidade. Muito embora, num aspecto similar, os respondentes tenham demonstrado iniciativa ao pensar formas para expandir a popularidade cultural da biblioteca, contribuindo mais ainda ao referir atividades diferentes das já realizadas na organização.

Sobre o significado de Educação patrimonial, alguns demonstram certo desconhecimento a respeito do tema, vinculando-o essencialmente à valorização de bens legados, mas sem indicar quais meios levariam as pessoas a valorizar esses itens considerados decorrentes duma herança. Enquanto outros associam-na à conscientização humana em relação à importância do patrimônio histórico-cultural que possui. Portanto, infere-se a existência do conhecimento parcial do tema, requerendo mais discussão e criticidade individual e coletiva.

Os respondentes acreditam ser importante a participação do bibliotecário no processo de divulgação e reconhecimento patrimonial das bibliotecas, vinculando seu desempenho preponderantemente à preservação do acervo, do ponto de vista cultural não indicaram como o profissional poderia atuar.

Foi possível verificar também a aplicabilidade e os benefícios da Educação patrimonial no processo de divulgação e reconhecimento das bibliotecas enquanto institutos patrimoniais, pois adaptando sua didática ao planejamento de atividades culturais há possibilidade de expandir a interação entre estas entidades e a sociedade. Dando o passo inicial nesse 
empreendimento, as bibliotecas demonstram preocupação por buscar através de ações culturais educativas, meios para obter maior envolvimento com os indivíduos.

Sob a égide da Educação patrimonial estes indivíduos têm a chance de explorar todas as faces da biblioteca e averiguar nesse contato a importância deste organismo sob os pontos de vista histórico, cultural e social, representando espaços de resguardo da memória e identidade nos locais onde estão inseridos. Conscientizando-se disso, indivíduos adquirem a capacidade de estabelecer efetivos vínculos de respeito e valorização com as bibliotecas, passando a valorizá-las como bens patrimoniais, usufruir de seus serviços, além de primar por sua preservação constituição histórico-cultural não somente nas esferas citadina e regional, mas nacional e internacional, mantidos pela biblioteca, cuja existência, possibilidades de obter conhecimento e enriquecimento cultural a partir de seu uso deveriam ser de ampla divulgação.

\section{REFERÊNCIAS}

BARDIN, Laurence. Organização da análise. In: Análise de conteúdo. Lisboa: Edições 70, 1977. p. 121-128.

BASTOS, Rossano Lopes. Educação patrimonial. 2006. Disponível em: <http://goo.gl/FZH8eZ>. Acesso em: 1 jun. 2015.

BIBLIOTHECA RIO-GRANDENSE. Estatuto da Biblioteca Rio-Grandense: aprovado em assembléia geral de 1ํ de setembro de 1941. Rio Grande, 1941.

BIBLIOTHECA Rio-Grandense: há 150 anos "semeia livros, livros a mancheia e manda o povo pensar". Boletim da Sociedade Amigos da Marinha do Rio Grande, Rio Grande, v. 4, n. 19, p. 8-13, jul./ago. 1996.

CARTERI, Karin Kreisman. Educação patrimonial e biblioteconomia: uma interação inadiável. Informação \& Sociedade, João Pessoa, v. 14, n. 2, p. 31-52, jul./dez. 2004. Disponível em: <http://goo.gl/0V1qu0>. Acesso em: 1 jun. 2015.

CUNHA, Roberta Caiado; CROASARA, Cruz Balestra. Educação patrimonial: patrimônio cultural, cidadania e educação. Interlink, [S.l.], v . 2, n .2, jul./dez. 2011. Disponível em: <http://goo.gl/iwbjUL>. Acesso em: 1 jun. 2015.

DIAS, Eduardo Wense. Biblioteconomia e ciência da informação: natureza e relações. Perspectivas em Ciência da Informação, Belo Horizonte, v. 5, n. esp., p. 67-80, jan./jun. 2000. Disponível em: <http://goo.gl/NxLlBo>. Acesso em: 10 jun. 2015.

GHIRARDELLO, Nilson; SPISSO, Beatriz; FARIA, Geraldo Mendes. Patrimônio histórico: como e porque preservar. São Paulo: Canal 6, 2008. Disponível em: <http://goo.gl/DezKMD>. Acesso em: 1 jun. 2015.

GRUNBERG, Evelina. Educação patrimonial: utilização dos bens culturais como recursos educacionais. Cadernos do CEOM, v. 14, n. 12, p.159-180, 2000. Disponível em: <http://goo.gl/0LJ8xi>. Acesso em: 1 jun. 2015.

Manual de atividades práticas de educação patrimonial. Brasília: IPHAN, 2007. Disponível em: <http://goo.gl/35Mw4k>. Acesso em: 1 jun. 2015.

HALBWACHS, Maurice. A memória coletiva. São Paulo: Revista dos Tribunais, 1990.

HORTA, Maria de Lourdes Parreiras. Guia Básico de Educação Patrimonial. Brasília: IPHAN: Museu Imperial, 1999.

IBGE. Rio Grande. Brasília, 2016. Disponível em: <http://goo.gl/l6hGxY>. Acesso em: 02 mar. 2016. 
MENTZ, Patricia. Lembranças concretas: a memória social através do patrimônio cultural edificado das bibliotecas. Monografia (Curso de Biblioteconomia) - Universidade Federal do Rio Grande do Sul, Porto Alegre, 2011. Disponível em:<http://goo.gl/8hZ5df>. Acesso em: 16 maio 2015 .

NORA, Pierre. Entre memória e história: a problemática dos lugares. Projeto História: revista do Programa de Estudos pós-Graduados em História e do Departamento de História, São Paulo, n. 10, p. 7-28, dez. 1993. Disponível em: <http://goo.gl/nbLg6a>. Acesso em: 16 maio 2015 .

PEDRAZA GRACIA, Manuel José. Algunas reflexiones sobre bibliotecas históricas o patrimoniales: nuevo paradigma entre los centros y servicios de información. Investigación Bibliotecológica, México, v. 28, n. 64, p. 33-50, set/dez. 2014. Disponível em: <http://goo.gl/2u8SrA>. Acesso em: 1 jun. 2015.

POLLAK, Michel. Memória e identidade social. Estudos históricos, Rio de Janeiro, v. 5, n.10, p. 200-212, 1992. Disponível em: <http://goo.gl/hDgXu0>. Acesso em: 16 maio 2015.

SANFELICE, Carla. Inventaire et problèmes actuels de la Bibliothèque Riograndense. HSAL, $\mathrm{n}$. 7, p. 9-12, premier semestre 1998. Disponível em: <http://goo.gl/uan7aF>. Acesso em: 23 nov. 2015.

SILVA, Josiane. Bibliotheca Rio-Grandense: trajetória e percalços de uma biblioteca mais que centenária. BIBLOS, Rio Grande, v. 25, n. 1, p. 59-67, dez. 2011. Disponível em:

<http://goo.gl/eFJlUz>. Acesso em: 23 nov. 2015.

YIN, Robert K. Estudo de caso: planejamento e métodos. 2. ed. São Paulo: Bookman, 2001. Disponível em: <https://goo.gl/6VIwPT>. Acesso em: 10 out. 2015.

Editores do artigo: Adilson Luiz Pinto, Rafaela Paula Schmitz e Enrique Muriel-Torrado 